\title{
PRODUÇÃO CIENTÍFICA BRASILEIRA EM ADMINISTRAÇÃO EM SAÚDE: ESCOPO E DIFERENCIAÇÃO
}

\section{BRAZILIAN SCIENTIFIC PRODUCTION IN HEALTH ADMINISTRATION: SCOPE AND DIFFERENTIATION}

Germany Gonçalves Veloso Fundação Getúlio Vargas - FGV-EAESP

germanyveloso@gmail.com

Ana Maria Malik

Fundação Getúlio Vargas - FGV-EAESP

ana.malik@fgv.br

Submissão: $02 / 11 / 2014$

Aprovação: 03/11/2015 


\title{
RESUMO
}

Evidências mostram que a área acadêmica de administração em saúde não tem uma definição clara e consensual sobre seu escopo e diferenciação. O objetivo do presente trabalho foi averiguar se existe uma concepção implícita compartilhada sobre a pesquisa na área. Como base teórica foi utilizado o referencial sobre campos científicos e, como método, foi utilizando a identificação de vocábulos distintivos/construção consensual. Realizou-se um levantamento, entre estudiosos de organizações de saúde, a fim de captar elementos conceituais característicos dos estudos da área, principais diferenciações (especialmente em relação à área de administração), e derivar um consenso implícito. Em paralelo, foi realizada também análise temática a fim de aumentar a validade dos achados. A partir da análise dos dados dos levantamentos foi possível constatar a existência de um consenso latente. Foi também possível elaborar uma definição tentativa sobre estudos em administração em saúde. O estudo pode contribuir para o desenvolvimento e fortalecimento da administração em saúde como área de pesquisa e ensino.

PALAVRAS-CHAVE: Administração. Saúde. Pesquisa. Definição. Escopo.

\begin{abstract}
Evidences show that health management academic research area does not have a clear and consensual definition of its scope and distinctive characteristics. The aim of this study was to investigate whether there is an implicit shared conception on the health administration research area. The study was based on the theoretical framework of scientific fields and used the distinctive lexicon identification/consensual conception as research technique. A survey among scholars interested in healthcare organizations was performed to capture characteristic conceptual elements of the area, its main distinctions (especially against the general administration), and to derivate an implicit consensus. In parallel, a thematic analysis was also performed in order to increase the validity of the findings. The analysis of survey data, allowed to perceive the existence of an underlying consensus and to draft a tentative definition of the area. The study may contribute to the development and strengthening of health administration as an area of research and teaching.
\end{abstract}

KEYWORDS: Administration. Health. Research. Definition. Scope. 


\section{INTRODUÇÃO}

Recentemente foi publicado um Fórum sobre a produção científica brasileira em Administração (BERTERO et al., 2013). Nesta, uma das áreas que frequentemente reivindica identidade própria é a Administração em Saúde (AS). Porém, como segue, a pesquisa em AS parece não ter escopo e diferenciação claros e compartilhados. Suas fronteiras se confundem com as de outras áreas científicas, como Administração de Empresas, Administração Pública, Medicina Preventiva, Saúde Coletiva, Saúde Pública, Economia e Economia da Saúde.

Alguns autores afirmam que a área de AS em si não tem sido alvo de investigação (PAIM; TEIXEIRA, 2006). Segundo outros, ela apresenta uma dificuldade para definição de seus limites (ALMEIDA, C., 2004). Tem limites bastante difusos (NOVAES, 2004). É caracterizada por diversidade e complexidade (ALMEIDA, M., 2004). "[N]ão tem uma estrutura conceitual bem definida, é marcadamente multidisciplinar, desenvolvida por múltiplos atores (academia, hospitais, governo)" (POLANCZIK, 2010, p. 3). Além disso, há o questionamento quanto a se existem especificidades da área, ou se seria desejável aplicar os conhecimentos já consagrados nos demais setores (MISOCZKY et al., 2009).

Entrevistas com membros dos conselhos editoriais de dois periódicos relacionados à AS também mostram que não há uma definição compartilhada das características distintivas dos estudos no campo. A análise de amostra de doze conhecidos livros-texto relacionados à área também reforçam esta impressão (conforme relatório da pesquisa original). Seus capítulos introdutórios não evidenciam uma definição clara, explícita e coletiva. O estudo de uma amostra das poucas definições disponíveis na literatura sobre pesquisas na área também demonstrou divergências. Algumas delas estão focadas no tipo de organizações (organizações de saúde). Outras, em funções administrativas (gestão da qualidade, gestão estratégica, gestão de recursos humanos, gestão orçamentária e financeira organização, financiamento, utilização e custos da atenção à saúde). Outras ainda, em objetivos (serviços de saúde adequados, efetivos, custo-efetivos, eficientes e aceitáveis ou concretização de princípios de organização da política). Além disso, enquanto algumas focam apenas serviços de saúde, outras englobam serviços e sistemas de saúde.

Desta forma, embora as evidências demonstrem que não existe uma definição clara, explícita e consensual sobre estudos em AS, é muito provável a existência de uma definição implícita, 
compartilhada e distintiva sobre pesquisas na área. Sua existência, presume-se, tem sido útil para o desenvolvimento da pesquisa, artigos, livros, encontros, com impacto inclusive na graduação, pós-graduação e cursos diversos na área.

Dentro deste contexto surge a questão do que especificamente é a pesquisa em AS, o que a caracteriza e o que a distingue das demais áreas adjacentes, principalmente em relação à Administração em geral. O objetivo deste trabalho portanto é investigar uma definição consensual tácita (englobando escopo e diferenciação) da pesquisa científica de AS, a partir da perspectiva de estudiosos de organizações de saúde. Acessoriamente, visa averiguar a visão que estudiosos de outras áreas tem sobre a AS.

\section{FUNDAMENTAÇÃO TEÓRICA}

Existe uma literatura desenvolvida dentro da sociologia do conhecimento sobre campos científicos e sua definição. Partiu-se principalmente de trabalhos que se baseiam em idéias como as utilizadas por Kuhn $(1970,2006,2011)$ sobre campos científicos e paradigmas. Diversos autores analisaram questões similares (HAGSTROM, 1965; LATOUR; WOOLGAR, 1979; MERTON; STORER, 1973). Há também outros autores citados em pesquisas sobre campos acadêmicos. As ideias de Bourdieu (BORDIEU, 1990, 2002, 2004), por exemplo, costumam ser utilizadas como referencial para a investigação.

Segundo os autores, um campo acadêmico tem suas fronteiras negociadas socialmente. Ele só existe porque um número crítico suficiente de pessoas acredita na sua existência e adota uma visão compartilhada de seu significado (ASTLEY, 1985; COLE, 1983). Esse significado compartilhado não pode ser dado como certo, pois vários fatores atuam para diluir o consenso. Esses fatores incluem heterogeneidade do treinamento dos investigadores, pressões intelectuais e hegemonia de campos adjacentes, além da constante evolução das teorias e do conhecimento (ASTLEY, 1985; WHITLEY, 1984).

Um campo científico é uma entidade que tem uma identidade coletiva e uma distintividade, frutos de forte consenso, implícito ou explicito, sobre sua essência. Esta definição de campo pode ter uma forte característica implícita, tácita, se houver ambiguidade em sua definição formal. Independente disso, é a identidade que dá aos seus membros um sentido fundamental de quem eles são enquanto comunidade e de como eles diferem de outras comunidades 
(DUTTON; DUKERICH, 1991). Comunidades acadêmicas podem ser consideradas verdadeiras tribos, com sua própria cultura, normas e linguagem (BECHER, 2001; GEERTZ, 1983). Para Kuhn (2011). Uma comunidade científica não necessita um modelo teórico unificado para existir, porém precisa de uma identidade compartilhada. Além disso, o escopo e as fronteiras de uma comunidade científica são fortemente influenciados pelo conhecimento dos especialistas e pelas normas de seus membros (SHAPIN, 1995).

Por outro lado, a linguagem, na forma de discurso científico, é o meio fundamental para tornar essa construção possível (BERGER; LUCKMANN, 1966). Ela é, portanto, a base onde se expressa a identidade distintiva compartilhada pelos membros de uma comunidade científica. Em função disso, o discurso, na forma de textos (artigos publicados ou trabalhos apresentados, por exemplo) pode servir para identificar o consenso sobre um campo. Para Kuhn (1970, 2006, 2011), por exemplo, os membros de diferentes campos acadêmicos são como membros de diferentes comunidades de linguagem. Ingressar em um grupo é antes de tudo aprender seu vocabulário (KUHN, 1970, 2006, 2011).

Especificamente no âmbito de Administração existem duas pesquisas publicadas recentemente com o objetivo de encontrar uma definição consensual sobre campos acadêmicos específicos. Um primeiro trabalho lida com a definição de "Administração Estratégica", e está publicado no periódico Strategic Management Journal (NAG; CHEN; HAMBRICK, 2007). Outro, que trata da definição de "Governo Eletrônico" (e-Government), encontra-se publicado no periódico International Review of Administrative Science (HU; PAN; WANG, 2010).

Ambos operacionalizam uma técnica para o objetivo de alcançar uma definição consensual de seus respectivos campos científicos. Trata-se de uma análise lexicográfica/construção conceitual (distinctive lexicon/consensual conception). Ela se baseia em análise de conteúdo de artigos avaliados nesses com pesquisadores dos respectivos campos e as consequentes análises estatísticas dos achados.

Análise de conteúdo ou análise textual é um conjunto de técnicas, com funções heurísticas e verificativas, de análise de material verbal, que se faz por meio de uma descrição objetiva, sistemática e quantitativa do conteúdo de comunicações, com a finalidade de interpretar estas comunicações (BARDIN, 2011, CAREGNATO; MUTTI, 2006). Uma assunção do método é 
que as palavras, frases ou temas (as unidades de análise) que mais se repetem são aquelas que refletem uma preocupação importante para aquele emissor. Outra premissa do método é que os textos têm um aspecto ou características aparentes em sua superfície, que podem ser descritos e analisados; e fatores que determinam essas características, que podem ser deduzidos logicamente (BARDIN, 2011). A análise de conteúdo trabalha com unidades de texto, buscando categorizá-las pode ser a palavra (análise lexicográfica), frases, proposições ou tema (análise temática), sendo que sobre o seu resultado é possível a utilização de técnicas de estatística (BARDIN, 2011; CAMPOS, 2004).

\section{METODOLOGIA}

A pesquisa propriamente dita incluiu o levantamento e análise iniciais das respostas de estudiosos de organizações de saúde e análises de conteúdo das respostas. Adicionalmente, foi feito pesquisa sobre a percepção de estudiosos de áreas adjacentes.

O levantamento com estudiosos de organizações de saúde baseou-se - com algumas adaptações - na técnica descrita nos trabalhos citados (NAG; CHEN; HAMBRICK, 2007; HU; PAN; WANG, 2010). Essa primeira abordagem objetivou captar a definição implícita sobre a área, uma vez que os respondentes tiveram que decidir se determinados artigos (resumo e título somente), que lhes foram apresentados, caracterizavam-se ou não como pertencentes à AS.

De forma geral, esta etapa teve as seguintes características. Foi feita seleção de artigos relacionados às organizações de saúde ou à saúde, o mais liberalmente definidos, em periódicos selecionados de Administração (RAE; RAE-eletrônica; RAUSP; RAC; RACEletrônica; RAP; e BAR). Coletou-se endereços eletrônicos de 237 pesquisadores e professores ligados ao estudo de organizações de saúde. Enviou-se a estes de mensagem explicando o projeto e seus objetivos. Realizou-se, com os mesmos, levantamento on-line com o auxílio do programa SurveyMonkey®. Além de perguntas relativas ao perfil dos respondentes, eles foram solicitados a ler os resumos/títulos dos artigos selecionados (sem revelar autores e instituições) e classificá-los a partir da pergunta "Este é um artigo de Administração/Gestão em Saúde?”. Os respondentes tinham opção de rotular os resumos/títulos usando as seguintes alternativas: (a) definitivamente não é; (b) provavelmente 
não é; (c) provavelmente é; (d) definitivamente é. Após 30 dias foi enviada nova solicitação para resposta. Coletou-se as respostas durante o período de 60 dias.

Para a seleção da amostra e número de artigos concluiu-se que o número de artigos a serem apresentados aos potenciais ranqueadores não deveria exceder a seis artigos (um deles, um filler, sem qualquer menção à área de saúde ou saúde em geral). Com base nesta restrição e em uma expectativa do número de respondentes para obter pelo menos cinco classificações por artigo, fez-se a seleção dos artigos dos periódicos citados, nos últimos prévios sete anos. Chegou-se ao total de 66 artigos.

Uma vez obtido um nível de concordância aceitável, os artigos foram analisados em relação ao seu conteúdo. Essa fase de análise (lexicográfica) teve, em linhas gerais, as seguintes características: foi feita entre os artigos classificados de forma mais consistente (excluindo-se os artigos onde houve maior desvio-padrão); identificação de vocábulos mais frequentes em cada tipo de artigo e identificação do vocabulário da área. Esta etapa foi apoiada por software (Concordance®).

A partir daí, foi realizada nova análise estatística para averiguar a associação ou correlação entre a frequência dos vocábulos, por um lado, e a categorização dos artigos feita pelos respondentes, por outro. As raízes dos vocábulos (lexemas) também foram, na sequência, categorizadas em termos de elementos (categorias conceituais) para uma nova averiguação de associação ou correlação com a classificação final dos artigos. Também a partir dos resultados foi gerado modelo de regressão logística com a finalidade de validar os achados. Análise temática foi realizada também com objetivo de validar os achados, por comparação dos resultados. O Quadro 1 é uma síntese da relação entre as perguntas da pesquisa e os métodos e técnicas empregados. O trabalho utilizou uma abordagem predominantemente a priorística com a utilização de hipóteses. Essas hipóteses são comentadas quando da discussão dos achados.

Quadro 1 - Relação entre as questões de pesquisa e as técnicas de análise de conteúdo e de estatísticas utilizadas.

\begin{tabular}{c|c|c}
\hline $\begin{array}{c}\text { Questão de } \\
\text { pesquisa }\end{array}$ & $\begin{array}{c}\text { Técnicas de análise de } \\
\text { conteúdo }\end{array}$ & Técnicas estatísticas \\
\hline $\begin{array}{c}\text { Existência de } \\
\text { consenso }\end{array}$ & -- & Porcentagem bruta de concordância (por diferentes \\
critérios); \\
Correlação Intraclasse
\end{tabular}




\begin{tabular}{|c|c|c|}
\hline Escopo da definição & & $\begin{array}{c}\text { Frequência dos lexemas e elementos conceituais (análise } \\
\text { lexicográfica); } \\
\text { Análises descritivas (análise temática) }\end{array}$ \\
\hline $\begin{array}{l}\text { Diferenciação da } \\
\text { definição }\end{array}$ & $\begin{array}{l}\text { Análise lexicográfica } \\
\text { Análise temática }\end{array}$ & $\begin{array}{c}\text { Associações e correlações dos lexemas e elementos } \\
\text { conceituais (análise lexicográfica); } \\
\text { Análises descritivas (análise temática); } \\
\text { Regressão logística (análises lexicográfica e temática) }\end{array}$ \\
\hline
\end{tabular}

Nota: Fonte: Elaborado pelos autores

Também foi realizado um levantamento com autores-chave, autoridades científicas e editores de periódicos de áreas de pesquisa adjacentes à AS. Neste caso, a finalidade foi captar: uma definição explícita, distinções e características gerais de AS. Esse levantamento teve uma abordagem mais exploratória, com perguntas abertas e respostas livres, sem limite de espaço para digitação. Foram selecionados 57 respondentes potenciais das áreas de Administração de Empresas, Administração Pública, Economia da Saúde e Economia. Foi realizado levantamento on-line, valendo-se das seguintes perguntas: (1) "Qual, na sua opinião, a definição e as características do campo acadêmico de Administração ou Gestão em Saúde?” e (2) "Quais, na sua opinião, as distinções entre o seu campo acadêmico de atuação e o campo acadêmico de Administração ou Gestão em Saúde?”.

\section{RESULTADOS E ANÁLISES INICIAIS}

Foram enviados 237 solicitações eletrônicas para resposta ao questionário. Foram obtidas 123 respostas válidas, o que corresponde a um percentual de 51,89\%. Entre os respondentes, predominam doutores (54\%), seguidos de mestres (37\%) e de profissionais com nível de pósgraduação não especificado (7\%). A Tabela 1 mostra o perfil dos respondentes, quanto a sua formação e atuação, se ocorre ou ocorreu em instituições públicas, privadas ou ambas.

Tabela 1 - Perfil dos respondentes entre estudiosos de organizações de saúde.

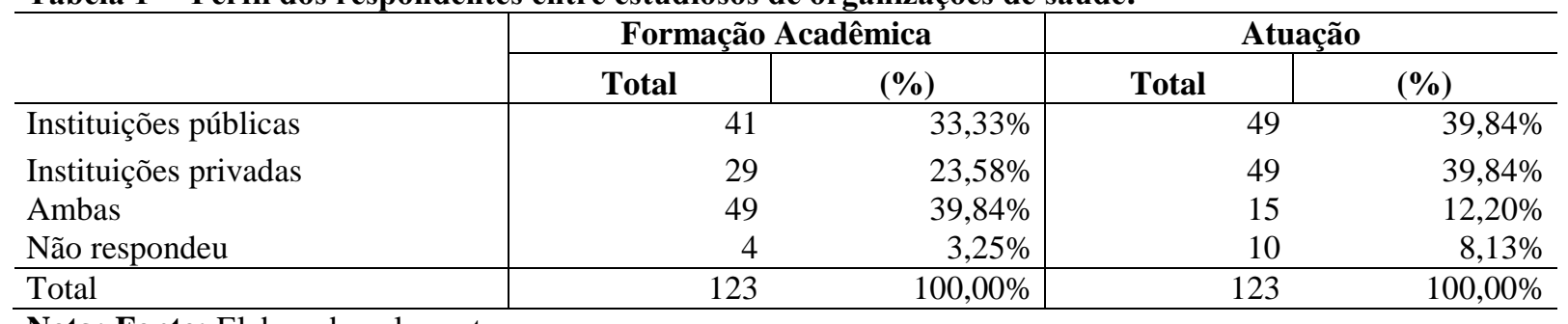

Nota: Fonte: Elaborado pelos autores

\section{Respostas}


Com os procedimentos descritos, o artigo que obteve o menor número de respostas alcançou oito classificações, número idêntico ao obtido no projeto de Nag, Chen e Hambrick (2007). O artigo que obteve maior número de avaliações alcançou onze.

O conjunto das respostas válidas foi tabulado e as respostas ou classificações foram convertidas em pontuação (rating) de 1 a 4, na seguinte ordem: "definitivamente não é", “provavelmente não é”, "provavelmente é” e "definitivamente é”.

Para avaliar o grau de consenso ou concordância entre as respostas foram utilizados três critérios: (1) a concordância bruta, (2) o nível de consenso "em torno" da resposta mais freqüente, (3) e a Intraclass Correlation (ICC). A correlação intraclasse que se aplica a presente pesquisa seria a absolute agreement, single measures, one-way random effect. Embora mantida, a ICC (que foi a estatística utilizada nos artigos tomados como referência) tem aplicação questionável no presente caso, pois ela encontra sua melhor utilização em variáveis contínuas. Em casos de variáveis ordinais-categóricas (como no presente estudo), muitos não vêem porque utilizar outra estatística que não a concordância bruta. Para Garson (2012), lidando com dados categóricos, o consenso é medido como o número de concordâncias dividido pelo número total de observações. Para Uebersax (2007), não há razão para preferir ICC em detrimento de taxas brutas de concordância, em se tratando de dados ordinais-categóricos. Ele define taxas brutas como o número ou porcentagem de concordância em cada categoria de classificação.

O Quadro 2 sintetiza a comparação dos achados em termos de concordância para os diferentes critérios descritos.

Quadro 2-Comparação dos diferentes critérios para análise de consenso das respostas

\begin{tabular}{c|c}
\hline & Resultado \\
\hline $\begin{array}{c}\text { Proporção de concordância bruta - considerando o grau de concordância em um único } \\
\text { ratingância maior ou igual a 50\% como critérios. }\end{array}$ & $73,08 \%$ \\
$\begin{array}{c}\text { Proporção de concordância bruta - considerando o grau de concordância "em torno" do } \\
\text { rating mais freqüente e concordância maior ou igual a 70\% como critérios. } \\
\text { Correlação intraclasse. }\end{array}$ & $84,61 \%$ \\
\end{tabular}

Notas: Fonte: Elaborado pelos autores

Nota 1 Testes de hipóteses para as proporções mostram que ambas são significativamente diferentes de $50 \%$ (ambos têm p-value abaixo de 0,05).

Nota 2 A interpretação para os resultados de ICC: 0-0,2 são considerados "ruins"; 0,21-0,4, "fracos"; 0,41-0,6, "regulares"; 0,61-0,8, "substanciais"; e acima de 0,8, "quase perfeitos" (LANDIS; KOCH, 1977). 


\section{Seleção dos artigos para análise de conteúdo}

Para efeito do trabalho, a inconsistência da classificação foi definida a partir da variabilidade de sua classificação. Uma variação maior que um desvio padrão (1 DP) entre as classificações dos avaliadores foi o critério para rotular os artigos como de categorização inconsistente. Os artigos de média maior que 3,0 tiveram neste trabalho classificação final (ou "tipo") de artigos de AS. Todos aqueles com média igual ou menor que 3,0, foram definidos como artigos de tipo NAS (não administração em saúde). Estas escolhas, ainda que possam ser vistas como arbitrárias, estão em linha com a metodologia dos artigos de referência para o presente estudo, e permitiram alcançar os elementos essenciais da definição da área. Tem-se 22 artigos com classificação inconsistente, 32 artigos de tipo AS e 12 artigos de tipo NAS.

\section{ANÁLISES DE CONTEÚDO}

A análise lexicográfica realizada segundo a técnica referida, buscando elencar os lexemas e elementos conceituais mais frequentes e mais relacionados aos artigos tipo AS. A técnica trabalhou inicialmente com lexemas, e depois com aglomeração destes em elementos conceituais. O uso dos elementos conceituais permitiu análises mais sofisticadas, como a modelagem de equação de regressão logística para descrever (e eventualmente, prever) o tipo de artigo. A análise lexicográfica foi conduzida com o apoio do software Concordance ${ }^{\circledR}$, que permite a elaboração e a padronização dos lexemas e sua respectiva contagem.

A seleção de lexemas também foi feita à luz dos objetivos do trabalho, desconsiderando-se palavras como "estudo", "pesquisa”, "trabalho", “artigo", "analisar”, “constatar", “investigar”, “concluir”, entre outras. Conjunções, preposições, advérbios, nomes próprios e alguns adjetivos também não foram de interesse para o desenvolvimento do trabalho. Desta forma, pode se chegar aos lexemas mais frequentes nos artigos em geral e nos artigos que foram categorizados como tipo AS (Tabela 2).

Para análise de correlação utilizou-se inicialmente cálculos de Correlação Biserial - Biserial Correlation (BSC). Porém, neste trabalho optou pela confecção de tabela de referência cruzada e cálculos de associação, pois a BSC pressupõe que as variáveis sejam continuas. Optou-se por trabalhar com duas variáveis dicotômicas: (1) a presença ou não de determinado 
lexema no artigo e (2) o tipo de artigo, AS ou NAS. Este tipo de estatísticas pediria o uso de Qui-Quadrado, mas como uma avaliação das tabelas de referência revelou que os pressupostos para a utilização do Qui-Quadrado não foram satisfeitos para todos os casos, optou-se pela utilização do Teste Exato de Fisher, solução amparada pela literatura (LEVIN, 1987; MAROCO, 2007). Por uniformidade, foi utilizado o Teste de Fisher para as análises de todos os elementos. A Tabela 3 mostra os resultados dos testes.

Tabela 2 - Lexemas mais frequentes nos resumos e títulos dos artigos com classificação final como de administração em saúde.

\begin{tabular}{c|c||c|c}
\hline Lexema & Total & Lexema & Total \\
\hline saúde & 95 & assistência & 15 \\
gestão & 51 & operacional & 14 \\
hospital & 45 & processo & 14 \\
pública & 42 & desenvolver & 13 \\
custos & 32 & qualidade & 13 \\
sistema & 32 & programa & 13 \\
implantar ou & & profissional & 12 \\
implementar & 27 & instituição & 12 \\
serviço & 25 & econômico & 12 \\
organização & 24 & financeiro & 12 \\
social & 22 & medicamentos & 11 \\
informação & 22 & estado & 11 \\
município & 21 & administração & 11 \\
modelo & 20 & família & 10 \\
médico ou medicina & 18 & estratégia & 10 \\
política & 16 & atividade & 10 \\
inovação ou novo & 16 & capacidade & 10 \\
tecnologia & 15 & Igualdade & 10 \\
recurso & 15 & cobertura & \\
\hline
\end{tabular}

Nota: Fonte: Elaborado pelos autores

Tabela 3 - Medidas de associação e correlação entre a presença de lexemas e o tipodo artigo na amostra selecionada.

\begin{tabular}{c|c|c|c}
\hline Lexema & Teste Exato de Fisher & \multicolumn{2}{|c}{ BSC } \\
\cline { 3 - 4 } & (Sig.) & (r biserial) & (Sig.) \\
\hline Organização & 0,005 & $-0,447$ & 0,002 \\
Hospital & 0,075 & 0,296 & 0,051 \\
Custos & 0,047 & 0,241 & 0,116 \\
Implantar & 0,083 & 0,295 & 0,052 \\
Empresa & 0,002 & $-0,331$ & 0,028 \\
produzir/produção & 0,003 & $-0,390$ & 0,009 \\
Justiça & 0,070 & $-0,283$ & 0,063 \\
Consumidor & 0,070 & $-0,317$ & 0,036 \\
\hline
\end{tabular}

Nota: Fonte: Elaborado pelos autores 
O procedimento para a análise foi feito por meio da formação de aglomerados de lexemas que se relacionam a determinados elementos conceituais, da mesma forma que foi realizado nos trabalhos utilizados como referencial. A elaboração do quadro forçou a definição de um lexema para exclusivamente um único elemento conceitual, apesar de em alguns casos, os lexemas poderem eventualmente ser alocados em mais de um elemento.

As tabelas seguintes mostram os elementos conceituais mais frequentes nos artigos classificados como tipo AS (Tabela 4). A Tabela 5 a seguir mostra a associação ou correlação da presença dos elementos conceituais com o tipo de artigo classificado, da mesma forma que foi realizada em relação aos lexemas.

A fim de oferecer base para validação dos achados, desenvolveu-se análise de regressão logística a partir dos resultados da análise lexicográfica. A constatação da significância das mesmas já oferece aspectos para discussão, porém a elaboração de um modelo de regressão logística permite também visualizar a atuação em conjunto destes elementos e validação dos achados.

Tabela 4 - Elementos mais frequentes nos resumos e títulos dos artigos com classificação final de administração em saúde.

\begin{tabular}{c|c||c|c}
\hline Elemento & Total & Elemento & Total \\
\hline Administração & 272 & Modelo & 20 \\
Saúde & 147 & Política & 18 \\
Sistema & 110 & Educação & 17 \\
Prestação & 98 & Equidade & 16 \\
Público & 96 & Aprendizagem & 16 \\
Econômico/Eficiência & 79 & Tecnologia & 13 \\
Organização & 36 & Qualidade & 13 \\
Capacidade/Recursos & 25 & Profissional & 11 \\
Social & 22 & Família & \\
Privado & 22 & & \\
\hline
\end{tabular}

Nota: Fonte: Elaborado pelos autores

Tabela 5 - Medidas de associação e correlação entre a presença de elementos e o tipo do artigo na amostra selecionada

\begin{tabular}{|c|c|c|c|}
\hline \multirow[t]{2}{*}{ Elemento } & \multirow{2}{*}{$\begin{array}{l}\text { Teste Exato de Fisher } \\
\text { (Sig.) }\end{array}$} & \multicolumn{2}{|l|}{ BSC } \\
\hline & & ( $\mathrm{r}$ biserial $)$ & (Sig.) \\
\hline Saúde & 0,075 & 0,353 & 0,019 \\
\hline Privado & 0,007 & $-0,364$ & 0,015 \\
\hline Prestação & 0,008 & 0,384 & 0,010 \\
\hline Organização & 0,015 & $-0,455$ & 0,002 \\
\hline Equidade & 0,047 & 0,260 & 0,088 \\
\hline Econômico-Financeiro & 0,181 & 0,295 & 0,052 \\
\hline
\end{tabular}

Nota: Fonte: Elaborado pelos autores 
O Quadro 3 mostra a equação gerada pela análise de regressão logística. Os resultados mostram que o modelo é significativo $(\mathrm{G}=25,582$, p-value $=0,000)$ e que tem adequada qualidade de ajustamento (Hosmer-Lemeshow $=1,58501, \mathrm{p}$-value $=0,954$ ). No modelo simplificado se observa que as variáveis Privado, Prestação e Organização são as de maior poder preditivo identificado nesta amostra de artigos (considerando um p-value $<0,1$ ).

Quadro 3-Equações de regressão geradas a partir das técnicas de análise lexicográfica.

TIPO = 0,3 + 0,5 - SAUDE - 1,8PRIVADO + 3,4PRESTAÇÃO - 2,0ORGANIZAÇÃO + 20,4EQUIDADE

Notas: Fonte: Elaborado pelos autores

Valores arredondados.

Foi realizada avaliação com erros, acertos e estatística de Kolgomorov-Smirnov (KS) para as diferentes probabilidades estimadas pelo modelo de regressão. Foi possível constatar que, no melhor ponto de corte, este modelo pode diferenciar em torno de 88,5\% dos artigos. A título de comparação, no trabalho de Nag, Hambrick e Chen (2007), o modelo ajustado apresentou uma porcentagem de acertos de $82 \%$ para avaliações de artigos de Estratégia.

Também com o objetivo de validar os achados da análise lexicográfica, foi realizada uma análise temática do conteúdo dos artigos (detalhes descritos no relatório original) que teve uma porcentagem de acerto de 91,1\%; bem próxima da porcentagem para a análise lexicográfica $(88,5 \%)$.

\section{Respostas de pesquisadores de áreas adjacentes}

Dos 57 solicitações eletrônicas para o questionário, foram obtidas 27 respostas, uma taxa de resposta de 47,37\%. Nove respostas foram de estudiosos de Economia (sete deles de Economia da Saúde); doze de Administração de Empresas; e seis de Administração Pública. A análise de conteúdo das respostas destas respostas mostrou a presença, em muitas delas, dos elementos conceituais expostos na definição implícita entre estudiosos de organizações de saúde.

De uma forma geral também, alguns comentários se repetiram, em maior ou menor grau, entre os respondentes das três áreas. Por estes comentários, a AS é considerada uma área: 
a) "interdisciplinar" e "multidisciplinar";

b) onde se deveria estimular o caráter multiprofissional;

c) "em construção" ou "ainda a ser definida";

d) que se identifica mais com um objeto de estudo;

e) de orientação mais prática que teórica;

f) com características muito peculiares que são um grande desafio à prática da gestão na área;

g) com muitos atores e interesses importantes;

h) com objetivos de difícil conciliação;

i) de grande importância social; e

j) que oferece muitas oportunidades de pesquisa e interações positivas com suas áreas adjacentes.

\section{DISCUSSÃO}

Parece existir um razoável consenso em torno de uma concepção compartilhada entre os respondentes. A ICC aponta um consenso "regular". O critério da proporção de concordância bruta maior ou igual a 50\% para uma única categoria de classificação mostra um resultado $(73,08 \%)$ que pode ser visto como substancial (por analogia aos termos usados na ICC) e, ao mesmo tempo, significativo sob o ponto de vista estatístico. Também foi significativa a proporção de concordância $(84,61 \%)$ considerando-se categorias de classificação adjacentes à maior concordância por artigo.

No conjunto, portanto, parece existir uma idéia ou concepção latente que justifique a conformidade das respostas dos estudiosos de organizações de saúde. Outra interpretação possível, respaldada pela literatura, é que o questionário montado conseguiu capturar uma proporção do consenso subjacente (equivalente à porcentagem obtida) (CORRAR; PAULO; DIAS FILHO, 2009).

Se na revisão bibliográfica foi evidenciado que não existe uma concepção explícita coletiva sobre AS, aqui foi possível perceber que, na amostra dos respondentes, há um entendimento implícito e compartilhado. Este entendimento, por sua vez, é um componente de paradigmas e também um dos elementos de campos científicos na acepção de Kuhn.

Os respondentes foram selecionados por compartilharem um objeto de estudo (organizações de saúde). Relembrando o que está descrito no referencial teórico de Kuhn, objetos de estudo podem fazer parte de diferentes especialidades (campos científicos), motivo pelo qual este foi o critério eleito para seleção de respondentes. É provável que os estudos de organização de 
saúde também podem ser objeto de pesquisa no âmbito de outros campos de ciência. A primeira especulação mais óbvia, a partir dos resultados, é a administração em geral. De qualquer forma pode-se sugerir também que existe um subgrupo de pesquisadores que estariam empenhados, de forma implícita, em solucionar um "enigma" ou um desafio compartilhado específico dentro de algo que se chama pesquisa em AS.

Em relação ao escopo da AS, pela técnica lexicográfica, inicialmente se analisou o aparecimento de lexemas que foram agregados em elementos conceituais, os quais foram a base principal de comparação com uma hipótese formulada para o escopo da área. Dos textos selecionados também emergiram vários elementos conceituais. A definição do que é um ponto de corte relevante é arbitrária. Observando os dados, e utilizando um cut-off de 10 de frequência, foi possível fazer um cotejamento dos resultados com a hipótese. O Quadro 4 mostra os conceitos com frequência acima deste ponto e que encontram correspondência com a hipótese. Estes são os elementos que caracterizariam a essência do escopo de pesquisas em AS. Para alguns elementos da hipótese, porém, não houve evidência significativa de suas presenças no escopo da área e um elemento poderia ser acrescido na concepção sobre ela, a partir dos achados.

Quadro 4 - Elementos conceituais mais frequentes nos artigos tipo administração de saúde

\begin{tabular}{cccc}
\hline \multicolumn{4}{c}{ Elementos conceituais } \\
\hline Administração & Saúde & Sistema & Prestação \\
Público & Econômico/Eficiência & Organização & Social \\
Privado & Modelo & Política & Equidade \\
Qualidade & & &
\end{tabular}

Nota: Fonte: Elaborado pelos autores

Alguns dos elementos mais frequentes entre os artigos tipo AS, na análise lexicográfica, não são exatamente o que está formulado na hipótese. O primeiro termo, Administração, diz respeito aos processos e estruturas "administrativas" ou organizacionais, mas também aos termos genéricos gestão e administração e a termos associados como diretor e executivo. Como exemplos desses processos tem-se: inovação, estratégia, plano, implantar, formular, marketing e decisão. Como exemplos dessas estruturas tem-se: estrutura, equipe e controle. Enquanto o lexema processo teve 14 aparições entre os artigos classificados como tipo AS, o 
lexema estrutura surgiu apenas 6 vezes, outro motivo pelo qual se optou por manter o elemento Administração, como uma categoria para os achados.

Foi mantido individualizado também o conceito Prestação, pois foi útil em análises descritas, pois é característico de alguns tipos de organização de assistência à saúde propriamente dita. O elemento Social é um termo muito relacionado aos conceitos de Público, Equidade e Política. O elemento Modelo relaciona-se com estudos teóricos ou teórico-empíricos, por isso também foi mantido.

Em relação ao conceito Qualidade, o conceito de Efetividade (com cinco aparições no total), como utilizado na área de saúde, está muito próximo ao de Qualidade Técnica e poderia ser acrescentado a este. Isto não foi feito porque o elemento Qualidade pode incluir tanto Qualidade Técnica quanto a Funcional. Além disso, o termo efetividade como usado em administração pode ser relacionado a estas duas idéias. Os dados da pesquisa lexicográfica não permitiram um estudo detalhado desta diferenciação.

Alguns elementos conceituais surgiram com frequência relevante (acima do ponto de corte estabelecido), porém sem correspondência com a hipótese. São elementos que "emergiram" a partir da pesquisa lexicográfica. Estes elementos são, por ordem de frequência de aparecimento: Capacidade/Recursos; Aprendizagem; Tecnologia; Educação; Profissional; e Família.

Analisando os textos dos resumos/títulos, os elementos Capacidade/Recursos e Aprendizagem poderiam ter sido também alocados no elemento Administração, mas como estão muito associados a correntes teóricas que explicam a utilização de recursos, foram mantidos separadamente. Embora eventualmente possa dizer respeito a recursos não exclusivamente organizacionais, a sua utilização está relacionada a processos organizacionais para extrair vantagem de recursos. Na verdade acabaram também mostrando sua utilidade para evidenciar a crescente influência destas mesmas perspectivas na área sob análise. A aplicação ou utilização de Tecnologia em organizações é outro tema de crescente interesse, e que poderia ter sido também alocado em administração, com ressalvas similares. 
Educação pode ser entendida como a disseminação do conhecimento oriundo de uma área específica, neste caso a própria pesquisa em AS. Ou seja, educação pode dizer respeito à divulgação dos conhecimentos adquiridos nesta área de estudo.

O termo Profissional embora possa ser visto como mais um conceito ligado aos demais conceitos vinculados à administração, é visto também sob uma nova perspectiva de avaliação. Isso pode dizer respeito, por exemplo, à avaliação da satisfação e rotatividade dos profissionais de saúde (além de outras perspectivas previstas na hipótese inicial).

Acredita-se que o elemento conceitual Família deveu seu freqüente aparecimento, às abordagens sobre o Programa de Saúde da Família (PSF), que por sua vez foi alocado sob Público. Ou seja, por uma característica da técnica, provavelmente houve o surgimento deste conceito que poderia ser alocado juntamente com iniciativas em um contexto público.

Considerando as limitações do trabalho e os critérios utilizados, a maioria dos elementos estão presentes como os elementos conceituais mais frequentes nos resumos/títulos dos artigos em ambas as análises de conteúdo executadas. No geral, os achados não foram significativos para os seguintes elementos: Financiamento (que pode estar incluindo em Políticas) e Instalações. Também não foi possível uma melhor análise sobre Qualidade em seus aspectos técnicos e funcionais. Pelo pequeno número de aparições, o lexema acesso foi reunido operacionalmente dentro do elemento Equidade, para efeito de categorização dos achados. Uma análise específica sobre tipos de organizações de saúde mostrou baixa frequência de artigos sobre operadoras de planos de saúde (OPS) entre os artigos tipo AS. Por outro lado, e também a grosso modo, o elemento que surgiu a partir dos dados, e que não estava contemplado na hipótese inicial, foi o elemento Profissional, principalmente como dimensão de avaliação.

Em relação à diferenciação ou a características distintivas em relação à administração em geral, observa-se que as relações postuladas para a maioria dos elementos postulados encontraram correspondência com os achados. Algumas relações relativas a alguns sub elementos, e que não foram claramente supostas, poderiam também ser acrescidas à diferenciação de AS. A definição do que é significação ou ponto de referência relevante da correlação ou associação foi novamente arbitrária. Neste trabalho foi utilizado, para os achados baseados em ambas as análises de conteúdo, um alfa crítico de 0,10 , a mesma escolha adotada no estudo utilizado com referencial. 
O Quadro 5 mostra uma comparação dos resultados relativos aos conceitos extraídos da análise lexicográfica, evidenciando se encontram ou não adequação com a hipótese. Especificamente, compara o esperado com o observado em termos de significância e do sinal da associação/correlação. Como se observa, de forma geral, há correspondência entre os achados e a hipótese formulada, com algumas observações que seguem.

Quadro 5 - Comparação das hipóteses estatísticas com os achados da análise lexicográfica.

\begin{tabular}{c|c|c|c}
\hline Categorias da hipótese & $\begin{array}{c}\text { Hipóteses (relação e } \\
\text { sinal esperados) }\end{array}$ & $\begin{array}{c}\text { Achados } \\
\text { (relação e sinal observados) }\end{array}$ & Intepretação \\
\hline Organização de Saúde & Positiva & $\begin{array}{c}\text { Positiva com Prestação e com } \\
\text { Saúde }\end{array}$ & Adequação \\
\hline Outras Organizações & Negativa & Negativa com Organização & Adequação \\
\hline Organização & Independente & Negativa com Organização & Sem adequação \\
\hline Sistemas & Positiva & Não significativo & Sem adequação \\
\hline Público/Privado & $\begin{array}{c}\text { Positiva com Público. } \\
\text { Negativa com } \\
\text { Privado }\end{array}$ & $\begin{array}{c}\text { Não significativo com Público. } \\
\text { Negativa com Privado (negativa } \\
\text { com os lexemas consumidor e } \\
\text { empresa). }\end{array}$ & $\begin{array}{c}\text { Adequação para } \\
\text { Privado }\end{array}$ \\
\hline Teórico/Empírico & Independente & Não significativo & Adequação \\
\hline Processos/Estruturas & Independente & Não significativo & Adequação \\
\hline Políticas & Positiva & Não significativo & Sem adequação \\
\hline Qualidade Técnica & Positiva & Não significativo & Sem adequação \\
\hline Qualidade Funcional & Negativa & Não significativo & Sem adequação \\
\hline Econômico-Financeiro & Independente & $\begin{array}{c}\text { Não significativo (positiva na } \\
\text { BSC) (positiva com o lexema } \\
\text { custos) }\end{array}$ & Adequação \\
\hline Equidade & \multicolumn{2}{|c|}{ Positiva } & Adequação
\end{tabular}

Nota: Fonte: Elaborado pelos autores

O conceito Organização da análise lexicográfica, por exemplo, é muito mais presente nos artigos classificados como NAS. Normalmente as organizações de saúde têm um termo bem específico que as designa em artigos. Normalmente se usa os termos "hospital" ou "prestador", o que se optou por manter. Por este mesmo motivo, o conceito Prestação é relacionado positivamente às pesquisas em AS. Alguns lexemas individualmente corroboram esta impressão, pois o lexema organização tem relação negativa e significativa, e o lexema hospital tem relação positiva e significativa com artigos tipo AS.

Além do elemento Prestação, o elemento Saúde pode, em menor escala, ser associado às organizações de saúde, quando fazendo referência a esta mesma expressão ou na expressão "planos de saúde". O conceito Saúde, como esperado, tem sinal de correlação positiva. Prestação, que inclui hospitais, serviços e assistência também. Assim, estes dois resultados 
sugerem a conformidade entre a hipótese (relação positiva de artigos de pesquisa em AS com organizações de saúde) e os achados.

Foi feita hipótese de uma relação positiva entre o tipo de artigo AS e o conceito Público e uma relação negativa com o conceito Privado. Os achados mostraram-se não significativos para a primeira relação e apontaram uma relação negativa e significativa para a segunda. A presença dos lexemas consumidor e empresa (lexemas relacionados ao conceito de Privado) tiveram, individualmente, relação negativa e significativa com classificação do artigo como AS, e foram os maiores influenciadores do achado para o elemento Privado.

Em termos de medidas ou critérios de avaliação ou de desempenho, esperava-se indiferença (em termos de correlação ou associação) em relação a aspectos Econômico-Financeiros, pois o mesmo seria inerente tanto a AS como a administração em geral. Os resultados não foram significativos para esta relação. Embora estes aspectos não tenham sido comprovados como um elemento diferenciador (o que apoia a hipótese formulada), pode-se perceber que artigos ligados a custos (um lexema) estão relacionados com AS de forma significativa. Este fato pode sugerir uma preocupação muito maior das pesquisas em AS com este tema, na comparação com a administração em geral. Uma interpretação possível para isso pode ser o fato do tema ter surgido como um tópico de recente interesse da área.

Esperava-se associação negativa com aspectos ligados à Qualidade Funcional, fato que não foi possível evidenciar pelos resultados obtidos. Esperava-se relação positiva com Qualidade Técnica, fato que também não foi possível demonstrar. Isto ocorreu, no geral, pois as evidências sobre critérios de avaliação podem ter sido prejudicadas pelo pequeno número de menções a elas nos resumos/títulos selecionados. Em relação ao elemento conceitual Equidade, da análise lexicográfica, os achados estão em linha com o formulado, pois evidenciou-se uma relação positiva e significativa com pesquisas em AS.

Por fim, sobre a análise lexicográfica, têm-se alguns achados que foram não-significativos, mas que podem corresponder às previsões de independência entre a classificação final e a presença dos elementos conceituais. São eles: Processos, Estruturas, Teórico e Empírico. Ou seja, não foram constatadas diferenças entre artigos AS e NAS no que diz respeito a estas variáveis. Os achados para os elementos Política e Sistemas (previstos relacionamentos positivos com pesquisas em AS) não foram significativos. 
Em relação à análise temática, seus achados vão ao encontro dos resultados da análise lexicográfica. Entre outros achados relevantes está o fato que embora a presença de organizações de saúde em artigos tenda a associá-lo com pesquisas em AS, observa-se, em alguns casos (cinco artigos), artigos sobre estas organizações que foram rotulados entre os artigos NAS. Nestes casos, não há outros elementos caracterizadores destes artigos como de $\mathrm{AS}$, fato que reforça a idéia presente na hipótese, qual seja: não basta estar ambientada em organizações de saúde para uma pesquisa ser definida como de AS. Em linha com este raciocínio, foi observado também que muitos artigos ambientados em organizações de saúde obtiveram classificação inconsistente. Ao todo são 18 artigos com esta característica. Adicionalmente, um tipo de organização de saúde não mostrou claramente relação com AS: as OPS não revelaram significativa associação ou correlação com este tipo de pesquisa.

Outra hipótese é que AS tem uma forma de avaliação de seu desempenho que é multidimensional. Isso encontraria amparo não somente na presença dos elementos anteriores, mais também em evidências de que artigos com avaliação em múltiplos critérios de resultado estariam positivamente relacionados à classificação final neste tipo. Os achados dão suporte a isto, já que os artigos com este tipo de abordagem - apesar de poucos - praticamente se limitam aos artigos com classificação final de AS.

Em síntese, não foram encontrados resultados claramente em contradição com a hipótese formulada. Na verdade, para alguns casos em que se esperavam relações, os achados foram não significativos. Por outro lado, os achados em relação especificamente ao lexema custos não haviam sido claramente previstos. Cabe lembrar ainda que as porcentagens de acertos com as previsões das diferentes técnicas servem como medida da validade dos achados, girando em torno de $90 \%$ para as duas técnicas.

\section{Definição tentativa}

Neste ponto, fez-se uma tentativa de articular uma definição sobre a área de AS. Foram usados como base os elementos das hipóteses que encontraram suporte nos achados e associados àqueles novos elementos que surgiram das análises.

Muitos destes elementos podem ocorrer em outras áreas e em suas respectivas definições. O que torna uma área específica como distinguível é uma reunião única de elementos ou 
características. A essência da concepção é uma configuração ímpar de características, em “intensão" e "extensão", e que distingue um conceito dos conceitos que lhes são associados (LARA, 2004). A definição é a tentativa de esquematizar esta fórmula-resumo que possibilita a identificação ou reconhecimento de estudos de AS. Ela é um esforço para integrar, na forma de uma sentença, os elementos conceituais identificados. Essa definição seria:

\begin{abstract}
Pesquisas acadêmicas em administração em saúde são... estudos teóricos ou empíricos sobre políticas, processos ou estruturas organizacionais em organizações ou sistemas de saúde com impacto em termos econômico-financeiros, de qualidade, de equidade ou de aspectos profissionais, em ambiente público ou privado.
\end{abstract}

\title{
7 CONCLUSÃO
}

De uma forma geral, o estudo conseguiu revelar, que para os artigos selecionados e com o auxílio da amostra de pesquisadores e professores, que existe uma idéia distinguível e latente sobre o que são as pesquisas acadêmicas em AS. Existem também algumas peculiaridades desta definição latente.

Por exemplo, vários artigos sobre organizações de saúde ou saúde em geral (que foi o critério de seleção dos artigos), não foram considerados como de AS ou tiveram classificação inconsistente. Outro aspecto é que a definição subjacente sobre AS também foi caracterizada como envolvendo tanto atuação em ambiente público como na iniciativa privada. Além de estudos de processos e estruturas organizacionais, ela também envolve estudos de políticas. Ela aborda o estudo de organizações, mas também o de sistemas de saúde, o que pode ser uma característica que se destaca em relação à administração em geral. Há também a presença de estudos teóricos e empíricos, no que não se diferencia da administração. E para concluir, muitas das características que são percebidas pelos próprios estudiosos de organizações de saúde fazem parte também da percepção de estudiosos de outras áreas acadêmicas adjacentes.

Esses resultados mostram uma concepção peculiar e diferente do senso comum sobre o que seja a área de pesquisa acadêmica em AS, principalmente em relação ao fato de esta não se limitar a ser um estudo de organizações de saúde. Na verdade, parece ser um conceito com muitas características. Destaca-se entre elas o fato de, em termos de critérios de desempenho ou objetivos, não haver uma primazia tão grande de stakeholders financeiros em detrimento de pacientes, da sociedade e dos profissionais de saúde. Por este mesmo motivo, a área parece 
mais associada a conceitos ligados à área pública e a uma avaliação multidimensional. Aparentemente contrariando também alguns autores, aspectos teóricos surgem tão frequentemente em artigos de AS como de administração em geral.

Entre as contribuições possíveis deste estudo estão: a criação de parâmetros para pesquisas bibliométricas sobre a área; sugerir novos debates sobre ela; fornecer uma definição que possa atrair mais pesquisas na área; ser uma base para o desenvolvimento de um consenso explícito sobre ela; ajudar o desenvolvimento futuro do campo em termos de pesquisa, educação e prática; e ser um substrato para fortalecer o posicionamento dentro do campo de administração.

Após a execução deste trabalho, podem-se ressaltar algumas limitações. Para parte dos elementos não foi possível observar associações ou correlações significativas. Um maior número e variabilidade de artigos poderia contemplar novos aspectos, porém neste caso, seria necessário dispor de um número maior de respondentes.

Outra limitação se deve ao fato que encontrar distinções da AS com outras áreas acadêmicas também poderia ser um objetivo justificável. Mas o foco em administração se deveu também igualmente à viabilização do projeto e ao interesse em compará-la com a administração em geral. A seleção dos artigos traz uma limitação, pois os artigos selecionados e os próprios periódicos de onde foram extraídos podem embutir vieses. Um viés é a qualidade dos artigos, pois não somente os melhores (e, portanto, publicados) seriam parte do que se entende por pesquisa em AS.

Por outro lado, este estudo também apresentou algumas evoluções em relação ao método originalmente utilizado. Pode-se citar, desconsiderando-se alterações menores: a realização de uma análise temática, a qual pode aumentar a validade dos achados; a investigação conjunta do escopo e diferenciação de uma área (enquanto o trabalho de Nag, Chen e Hambrick (2007) focou mais a diferenciação do campo; Hu, Pan e Wang (2010) abordaram mais o escopo). O uso de diferentes técnicas de estatísticas que foram julgadas mais adequadas para o presente estudo (como o uso de medidas brutas de concordâncias e diferentes técnicas para avaliação de associação de dados categóricos) também são desenvolvimentos em relação à técnica original. 


\section{REFERÊNCIAS}

ALMEIDA, C. Debate sobre o artigo de Hillegonda Maria Dutilh Novaes. Cad. Saúde Pública, Rio de Janeiro, v. 20, Sup. 2, p. 158-159, jan, 2004.

ALMEIDA, M. F. Cad. Saúde Pública, Rio de Janeiro, 20 Sup 2: S147-S173, jan, 2004.

ASTLEY, W. G. Administrative science as socially constructed truth. Administrative Science Quarterly, Ithaca, NY, v. 30, n. 4, p. 497-513, dec, 1985.

BARDIN, L. Análise de Conteúdo. São Paulo: Edições 70, 2011.

BECHER, T. Academic tribes and territories: Intellectual enquiry and the cultures of disciplines. Bristol, PA: Open University Press, 2001.

BERGER, P. L.; LUCKMANN, T. The social construction of reality: A treatise in the sociology of knowledge. Garden City, NY: Double Day, 1966.

BERTERO, C. O.; VASCONCELOS, F. C.; BINDER, M. P.; WOOD JR, T Produção científica brasileira em administração na década de 2000. RAE, São Paulo, v. 53, n. 1, p. 12 20, jan/fev, 2013.

BOURDIEU, Pierre. Coisas Ditas. São Paulo: Brasiliense, 1990.

BOURDIEU, Pierre. Para uma sociologia da ciência. Lisboa: 2004.

BOURDIEU, Pierre. Pierre Bourdieu entrevistado por Maria Andrea Loyola. Rio de Janeiro: UERJ, 2002.

CAMPOS, C. J. G. Método de análise de conteúdo: ferramenta para a análise de dados qualitativos no campo da saúde. Rev. Bras. Enferm., Brasília (DF), v. 57, n. 5, pp. 611-14, set/out, 2004.

CAREGNATO, R. C.; MUTTI, R. Pesquisa qualitativa: análise de discurso versus análise de conteúdo. Texto Contexto Enferm, Florianópolis, v. 15, n. 4, pp. 679-684, out-dez, 2006.

COLE, S. The hierarchy of the sciences?. American Journal of Sociology, Chicago, v. 89, n. 1, p. 111-139, jul, 1983.

CORRAR, L. J.; PAULO, E.; DIAS FILHO, J. M. (Coord.). Análise Multivariada. São Paulo: Atlas, 2009.

DUTTON, J. E.; DUKERICH, J. M. Keeping an eye on the mirror: Image and identity in organizational adaptation. Academy of Management Journal, Texas, v. 34, n. 3, p. 517-554, set, 1991.

GARSON, G. D. Reliability. Asheboro, North Carolina: Statistical Publishing Associates, 2012. 
GEERTZ, C. Local knowledge: further essays in interpretive anthropology. New York: Basic Books, 1983.

HAGSTROM, W. O. The Scientific Community. New York: Basic Books, 1965.

HU, G.; PAN, W.; WANG, J. The distintive lexicon and consensual conception of eGovernment: an exploratory perpective. International Review of Administrative Science, Thousand Oaks, v. 76, n. 3, p. 577-597, set, 2010.

KUHN, T. S. A estrutura das revoluções científicas. Tradução: Beatriz Vianna Boeira e Nelson Boeira. 10 ed. São Paulo: Perspectiva, 2011.

KUHN, T. S. O caminho desde a estrutura. São Paulo: Editora UNESP, 2006.

KUHN, T. S. The structure of scientific revolutions. 2nd Ed. Chicago, IL: University of Chicago Press, 1970.

LANDIS RJ, KOCH GG. The measurement of observer agreement for categorical data. Biometrics, v. 33, pp. 159-74, 1977.

LARA, M. L. G. Diferenças conceituais sobre termos e definições e implicações na organização da linguagem documentária. Ci. Inf., Brasília, v. 33, n. 2, p. 91-96, maio/ago. 2004

LATOUR, B.; WOOLGAR, S. Laboratory life: The social construction of scientific facts. Beverly Hills: Sage Publications, 1979.

LEVIN, J. Estatística aplicada a ciências humanas. 2. Ed. São Paulo: Harbra, 1987.

MAROCO, J. Análise Estatística: com utilização do SPSS. Lisboa: Silabo, 2007.

MERTON, R. K.; STORER, N. W. The sociology of science: Theoretical and empirical investigations. Chicago: University of Chicago Press, 1973

MISOCZKY, M. C.; VECINA NETO, G.; JUNQUEIRA, L. P.; MALIK, A. M. Fórum Administração e Saúde. RAE, São Paulo, v. 49, n. 4, out/dez, 2009.

NAG, R.; HAMBRICK, D. C.; CHEN, M. What is strategic management, really? Inductive derivation of a consensus definition of the field. Strategic Management Journal, Chicago, v. 28, nº 9, p. 935-955, mar, 2007.

NOVAES, H. M. D. Pesquisa em, sobre e para os serviços de saúde: panorama internacional e questões para a pesquisa em saúde no Brasil. Cadernos de Saúde Pública, Rio de Janeiro, 20 Sup 2, S147-S173, jan., 2004.

PAIM, J. S.; TEIXEIRA, C. F. Política, planejamento e gestão em saúde: balanço do estado da arte. Rev Saúde Pública, São Paulo, v. 40, N. Esp, p. 73-78, ago., 2006.

POLANCZIK, C. A. Pesquisa em serviços de saúde: precisamos valorizar essa tendência! Rev. HCPA, Porto Alegre, v. 30, n. 1, p. 3-4, abril, 2010. 
SHAPIN, S. Here and everywhere: Sociology of scientific knowledge. Annual Review of Sociology, Palo Alto, v. 21, p. 289-321, ago, 1995.

UEBERSAX, J. Intraclass correlation and related methods. 2 Abril, 2007. Disponível em: <http://www.john-uebersax.com/stat/icc.htm>. Acesso em: 22 nov, 2011.

WHITLEY, R. The fragmented state of management studies: Reasons and consequences. Journal of Management Studies, Malden, v. 21, n. 3, p. 331-348, jul, 1984. 